\title{
Agri-food Ecosystems and Sustainable Development Goals: A Case Study by Italy
}

\author{
Prof. Dr. Nadia Cipullo \\ Link Campus University, Italy
}

\begin{abstract}
The paper aims at showing how innovations in agri-food business models influence the corporate sustainability of rural ecosystems, assuring the attainment of specific sustainable development goals. The purpose is achieved through a case study method, using a relevant farmhouse and agritourism "Anna dei Sapori" located in the Cilento Bio-District - rich of bio-cultural diversity and homeland of the Mediterranean Diet, Intangible Cultural Heritage by the UNESCO - in Italy. Results show as all corporate processes are managed according to agroecological principles, introducing useful innovations. The goal demonstrates the impact of this thrilling "philosophy", based on a circular and holistic approach, on environmental, sociocultural and economic dimensions of sustainability, and the achievement of specific Sustainable Development Goals and targets.
\end{abstract}

Keywords - agri-food ecosystem; innovation; SDG; sustainable business model; agroecology; bio-cultural diversity.

The global food system is at a crossway. According to the FAO (FAO, 2018), 821 million people are still hungry, and it is clear that the agriculture and food systems are not meeting the world's demand for food. The SDG2, which goal is to end hunger and all forms of malnutrition by 2030, is not respected. A new design thinking is urgent in order to address Agenda 2030 and SDGs for the achievement of food security and nutrition (FSN). Sustainable food systems are needed to ensure appropriate food production and to reduce losses and waste, while also safeguarding human and environmental health and better livelihoods with less environmental consequences. In this scenario, innovation in the agri-food sector and in business models of rural firms is crucial in order to respond to all the challenges faced.

In particular, agri-food innovation refers to the process and its changes by which individuals, communities or organizations modify the design, the production or the recycle of goods and services (Altieri, 1995; Gliessman, 2007) in the rural system. It includes transformations in practices, markets and institutional arrangements, which may promote new networks of food production, processing, distribution and consumption for challenging the status quo (De Bernardi and Azucar, 2020). Thus, the emergence of a new paradigm allows for the recognition of the agroecology as a sustainable agriculture's business model, supporting ecological relations in farming systems and the safeguard of the bio-cultural diversity (Pimbert, 2018), protecting the environment and the society (Lowrance et al., 1984). It is a dynamic and holistic concept that has gained prominence in scientific, agricultural and political discourse in recent years. It is progressively promoted for the transformation of food systems by applying ecological principles to agriculture and ensuring a regenerative use of natural resources and ecosystems while also tackling the need for socially equitable food systems. It has 
evolved over recent decades to encompass whole agriculture and food systems. Now, it represents a multidisciplinary field that includes ecological, sociocultural, technological, economic and political dimensions of food systems, from production to consumption.

In the context of Corporate Social Responsibility and innovation in agri-food business models (Tell et al., 2016), agroecological principles are directed to increase the resilience and the sustainability of organizations operating in rural ecosystems (Lamine, 2014). Thus, they are an effective instrument to reach specific SDGs (Petersen and Arbenz, 2018) by means of waste reduction and circularity (Lemaire and Limbourg, 2019).

The paper aims at showing how innovations in agri-food business models influence the corporate sustainability in rural ecosystems, assuring corporate social responsibility (CSR) and sustainable development goals (SDGs). Adopting a case study method (Yin, 2014), the agroecological principles (FAO, 2018a; HLPE, 2019) were used. The goal is to demonstrate the impact of this thrilling "philosophy", based on a holistic and circular point of view, on the different and interconnected dimensions of sustainability, and the achievement of specific SDGs and targets.

The methodology is based on the Yin's (2014) case study approach, in order to answer the research question: How are agri-food business models influenced by agroecological innovations to assure corporate sustainability and SDGs?

The application of the case study method is a relevant way to understand "a how or why question is being asked about a contemporary set of events over which the investigator has little or no control" (Yin, 2014, p. 14). Case studies grant a better analysis of a "real-world case" (Ridder et al., 2014) and they help to bridge the gap between academia and practice (Massaro et al., 2018). They seem ideal when the context is observable and transparent. Therefore, it is argued that such methodology is appropriate considering the specific research question of this research.

The case study concerns the farmhouse of Anna Nigro, "Anna dei Sapori". It is located in Castelnuovo Cilento, in the Cilento Bio-District and in the National Park of Cilento, Vallo di Diano and Alburni (Campania Region), in the south of Italy. The Cilento has been awarded four UNESCO recognitions: the National Park of Cilento, Valle di Diano and Alburni is included in the lists of UNESCO World Heritage Sites, UNESCO Geoparks as well as in the UNESCO Program on Man and the Biosphere (MAB). Additionally, in the Cilento Ancel Keys conducted his studies on the Mediterranean Diet, which was later (2010) recognized by UNESCO as an intangible heritage of humanity. In the BioDistrict context, farmers, citizens and public administrators have formed a pact for the sustainable management of local resources. The territory is rich of traditions and agrobiodiversity and seems very suitable for the adoption of agroecological principles. Indeed, the FAO underlined the importance of biodiversity for food and agriculture (FAO, 2019).

In order to assure the validity and data triangulation (Yin, 2014), data of different types are gathered from multiple sources. More in detail, interviews with the owner/founder, Anna Nigro, and public data released by the business, through the website and social media (Facebook, Instagram) were used. Moreover, third parties' opinions about the activity were searched: articles published in the press, comments and posts of people retrieved from social media. To assure internal and external validity, as recommended by Yin (2014), a logical model and theory confrontation were applied.

After the data collection, Anna dei Sapori's business model's activities have been grouped into four macro areas which also represent useful keywords:

1. Multifunctionality;

2. Circularity; 


\section{Cooperation and Education;}

4. Promotion of Bio-Cultural Diversity.

They allow to better identify the connection among activities, agroecological principles of FAO and HLPE (Tables 1 and 2) and SDGs/targets.

In Table 3, the identified connections among four Anna dei Sapori activities, elements and principles of agroecology as defined by the two Institutions and, finally, SDGs and specific targets that can be achieved through the adoption of this innovative tool for the management of agri-food ecosystems are reported.

The first aspect to underline is the not perfect coincidence among the principles/elements and the economic, social and environmental aspects of SDGs. Indeed, sustainability is a holistic and multidimensional concept, that cannot be categorized in strict classes.

For what concerns the Multifunctionality, it can be analyzed in terms of diversity and economic diversification. SDGs reached are 8 (promote sustained, inclusive and sustainable economic growth, full and productive employment and decent work for all), 12 (ensure sustainable consumption and production patterns) and 2 (end hunger, achieve food security and improved nutrition and promote sustainable agriculture). As a matter of fact, Anna dei Sapori, a small-scale producer (2.3), provides decent and pleasant work conditions to family members and external collaborators (8.5), by promoting sustainable tourism and local products (8.9). All operations are managed according to principles of sustainable consumption (12.a) and sustainable tourism (12.b).

The Circularity covers the environmental dimension and principles of synergy, recycling, efficiency and input reduction. It allows to achieve SDGs 12 and 15 (protect, restore and promote sustainable use of terrestrial ecosystems and halt biodiversity loss). Anna dei Sapori uses resources in an efficient way (12.2) and reduces food waste (12.3). In the farmhouse, green chemicals (12.4) are mainly used, as the whole corporate vision is devoted to the environmental sustainability (12.6). The agroecological approach ensures the conservation, restoration and sustainable use of the terrestrial ecosystem (15.1).

Cooperation and Education activities attain the socio-cultural dimension. Indeed, they promote the connectivity, the sharing of traditional knowledge, the attention towards a healthy and diversified diet (the Mediterranean one) and the management of groups and networks at different levels (schools, Universities, social and inclusive associations and farmers organizations). SDGs affected are 4 (ensure inclusive and equitable quality education and promote lifelong learning), 10 (reduce inequality within and among Countries) and 12. The educational activities, provided in an explicit or implicit way (stories and anecdotes told by Anna during meals) are the basis to reach a quality and inclusive education (4.4), to spread an environmental awareness (12.8) and even to achieve social inclusion (10.2) through the cooperation with La Tela (a laboratory of an artisanal and social nature) and hospitality/education on the Bio-district concepts provided also to foreign student (from Ghana). The last macro area of activities is connected to the promotion of Bio-Cultural Diversity. Even in this case, dimension involved is mainly the socio-cultural one. Anna dei Sapori has a strong attention towards the biodiversity conservation, through the control of ancient seeds, land, water and food traditions. In this way, it encourages the achievement of SDGs 2, 8 and 11 (make cities and human settlements inclusive, safe, resilient and sustainable). The safeguard of bio-cultural diversity (2.5) promotes a more resilient agriculture (2.4) and, at the same time, protects the cultural and national heritage (11.4). The commercial means are the sustainable tourism offer and the sale of local products (8.9). 
To sum up, it is possible to state that the adoption of agroecology principles for the management of agri-food ecosystems is an effective tool and a means that can be profitably used to reach UN's goals of sustainable development. The territory in which the farmhouse operates has proven itself suitable to the study, because of the great bio-cultural diversity existing, the attention towards organic and natural techniques of production and the promotion of healthy foods and diets. Anna dei Sapori proved that multifunctionality, circularity, education, cooperation and the promotion of bio-cultural diversity contribute to the achievement of SDGs in a multidimensional and interconnected way. Indeed, the sustainability concept cannot be categorized in strict classes and each area of interest (economic, environmental and social) is strictly connected to others. The attainment of SDGs should go through the adoption of business models that are based on multidimensional and holistic principles. In the agri-food sector, this means to embrace the ecosystem approach (like the agroecological one), on the basis of which environment/landscape, animals, people and their cultural traditions are interconnected and results/wastes of each stage of production/consumption can be put back into circulation in a profitable manner. In this way the circular economy is nourished, and waste is reduced.

The study is a novel contribution to the research streams of CSR (Welford, 2005) and innovation in the agri-food sector (León-Bravo et al., 2019), as it shows how innovative business models and "philosophies" can better the sustainability and the resilience of terrestrial ecosystems and, in this way, can contribute to the achievement of SDGs. It will represent the basis of future studies and researches by Academics and practitioners, and applications from farmers interested in experimenting new strategies for a more sustainable agriculture. Indeed, in light of the recent COVID-19 pandemic, it is supposed that local food producers and farmers will be forced to rethink and adapt their business models, working on increased sustainability solutions. In line with the EU Green New Deal (2019), local authorities and organizations could use this moment to focus on shaping a more sustainable future, rethinking how "to protect, conserve and enhance the EU's natural capital, and protect the health and well-being of citizens from environment-related risks and impacts". Moreover, as stated in the recently released EU Biodiversity Strategy for 2030, "the recent COVID-19 pandemic makes the need to protect and restore nature all the more urgent. The pandemic is rising awareness of the links between our own health and the health of ecosystems". The new attention towards interdependencies in each stage of production and consumption will probably lead to a greater awareness of food independence in communities and will hopefully reinforce the role of local producers and farmers to boost the recognition of local communities' link with their territories, thus enhancing the local economy. The work on an integrated management of terrestrial ecosystems and local heritage will support regions and rural territories to find their local distinctiveness and identity, opening the way to increased options for the sustainable tourism.

The main limitation of this paper lies in context characteristics, derived from the specific case study based on a single business and on a territory with its peculiarities. Future research could profitably test same assumptions on different territorial contexts. 


\section{References}

1. Altieri, M. A., 1995. Agroecology: the science of sustainable agriculture. Boulder, USA, Westview Press.

2. De Bernardi P., Azucar, D., 2020. Innovation in Food Ecosystems. Entrepreneurship for a Sustainable Future. Springer.

3. FAO, 2018. Sustainable food systems: Concept and framework. Retrieved from http://www.fao. org/3/ca2079en/CA2079EN.pdf

4. FAO, 2018a. FAO's work on agroecology. A pathway to achieving the SDGs.

5. FAO, 2019. The state of the World's biodiversity for food and agriculture. Rome.

6. Gliessman, S.R., 2007. Agroecology: the ecology of sustainable food systems. $2^{\text {nd }}$ edition. Boca Raton, USA, CRC Press.

7. HLPE, 2016. Sustainable agricultural development for food security and nutrition: what roles for livestock? A report by the High Level Panel of Experts on Food Security and Nutrition of the Committee on World Food Security. Rome.

8. Lamine, C., 2014. Sustainability and Resilience in Agrifood Systems: Reconnecting Agriculture, Food and the Environment. Sociologia Ruralis, 55(1), 41-61.

9. Lemaire, A., Limbourg, S., 2019. How can food loss and waste management achieve sustainable development goals? Journal of cleaner production, 234, 1221-1234.

10. León-Bravo, V., Moretto, A., Cagliano, R., Caniato, F., 2019. Innovation for sustainable development in the food industry: Retro and forward- looking innovation approaches to improve quality and healthiness. Corporate Social Responsibility and Environmental Management, 26, 1049-1062.

11. Lowrance, R., Stinner, B. R., \& House, G. J., 1984. Agricultural Ecosystems: Unifying Concepts. Wiley-Interscience, New York.

12. Massaro, M., Dumay, J., Garlatti, A., Dal Mas, F., 2018. Practitioners' views on intellectual capital and sustainability: From a performance-based to a worth-based perspective. Journal of Intellectual Capital, 19 (2), 367-386.

13. Petersen, P., \& Arbenz, M., 2018. Scaling up agroecology to achieve the SDGs: a political matter. Farming Matters, 3, 6-9.

14. Pimbert, M. P., 2018. Food sovereignty, agroecology and biocultural diversity. Constructing and contesting knowledge. Routledge.

15. Ridder, H.-G., Hoon, C., McCandless Baluch, A., 2014. Entering a dialogue: Positioning case study findings towards theory. British Journal of Management, 25(2), 373-387.

16. Tell, J., Hoveskog, M., Ulvenblad, P., Ulvenblad, P.-O., Barth, H., Ståhl, J., 2016. Business model innovation in the agri-food sector: a literature review. British Food Journal, 118(6), 1462-1476.

17. Welford, R., 2005. Corporate Social Responsibility in Europe, North America and Asia: 2004 Survey Results. The Journal of Corporate Citizenship, 17, 33-52.

18. Yin, R. K., 2014. Case Study Research: Design and Methods. SAGE, Los Angeles. 


\section{Tables}

\begin{tabular}{|l|}
\hline Diversity \\
\hline Co-creation and sharing of knowledge \\
\hline Synergy \\
\hline Efficiency \\
\hline Recycling \\
\hline Resilience \\
\hline Human and social values \\
\hline Culture and food traditions \\
\hline Responsible governance \\
\hline Circular and solidarity economy \\
\hline
\end{tabular}

Table 1: FAO ten elements of agroecology (2018)

\begin{tabular}{|l|l|}
\hline \multicolumn{1}{|c|}{ HLPE Principle } & \multicolumn{1}{|c|}{ Corresponding FAO element } \\
\hline \multicolumn{1}{|c|}{ Improve resource efficiency } \\
\hline 1. Recycling & Recycling \\
\hline 2. Input reduction & Efficiency \\
\hline \multicolumn{2}{|c|}{ Secure social equity/responsibility } \\
\hline 3. Soil health & / \\
\hline 4. Animal health & / \\
\hline 5. Biodiversity & Diversity \\
\hline 6. Synergy & Synergy \\
\hline 7. Economic diversification & knowledge \\
\hline & $\begin{array}{l}\text { Human and social values; } \\
\text { Culture and food traditions }\end{array}$ \\
\hline 8. Co-creation of knowledge & / \\
\hline 9. Social values and diets & Circular and solidarity economy \\
\hline 10. Fairness & Responsible governance \\
\hline 11. Connectivity & / \\
\hline $\begin{array}{l}\text { 12. Land and natural resource } \\
\text { governance }\end{array}$ & \\
\hline 13. Participation &
\end{tabular}

Table 2: Consolidated set of 13 agroecological principles of HLPE (2019) 


\begin{tabular}{|l|l|l|l|}
\hline \multicolumn{1}{|c|}{$\begin{array}{c}\text { "Anna dei Sapori" } \\
\text { activities }\end{array}$} & \multicolumn{1}{|c|}{$\begin{array}{c}\text { FAO 10 Elements } \\
\text { (2018) }\end{array}$} & \multicolumn{1}{|c|}{$\begin{array}{c}\text { HLPE 13 } \\
\text { Principles } \\
\text { (2019) }\end{array}$} & \multicolumn{1}{|c|}{ SDGs/Targets } \\
\hline Multifunctionality & Diversity & Principle 7 & $\begin{array}{l}\text { SDG 2 (2.3) } \\
\text { SDG 8 (8.5; 8.9) } \\
\text { SDG 12 (12.a; 12.b) }\end{array}$ \\
\hline Circularity & $\begin{array}{l}\text { Synergy; } \\
\text { Recycling; } \\
\text { Efficiency; } \\
\text { Circular and solidarity } \\
\text { economy. }\end{array}$ & Principles 1; 2; 6 & $\begin{array}{l}\text { SDG 12 (12.2; 12.3; 12.4; 12.6) } \\
\text { SDG 15 (15.1) }\end{array}$ \\
\hline Cooperation/Education & $\begin{array}{l}\text { Co-creation and } \\
\text { sharing } \\
\text { knowledge; } \\
\text { Human and social } \\
\text { values; } \\
\text { Culture and food } \\
\text { traditions. }\end{array}$ & Principles 8; 9; 11 & $\begin{array}{l}\text { SDG 4 (4.4) } \\
\text { SDG 10 (10.2) } \\
\text { SDG 12 (12.8) }\end{array}$ \\
\hline $\begin{array}{l}\text { Promotion of Bio- } \\
\text { Cultural Diversity }\end{array}$ & $\begin{array}{l}\text { Diversity; anan social } \\
\text { values; and food } \\
\text { Culture and } \\
\text { traditions. }\end{array}$ & Principles 5; 9 & SDG 2 (2.4; 2.5); \\
SDG 8 (8.9) \\
SDG 11 (11.4)
\end{tabular}

Table 3: Connections among Anna dei Sapori activities, agroecological elements/principles and SDGs/Targets 